\title{
Review
}

\section{Threshold for Genotoxic Carcinogens: The Central Concern in Carcinogenic Risk Assessment}

\author{
Shoji Fukushima ${ }^{1,3}$, Min Wei $^{2}$, Anna Kakehashi ${ }^{2}$ and Hideki Wanibuchi ${ }^{2}$ \\ 1Japan Bioassay Research Center, Japan Industrial Safety \& Health Association, Kanagawa, Japan \\ 2Department of Pathology, Osaka City University Graduate School of Medicine, Osaka, Japan
}

(Received May 24, 2012; Revised June 9, 2012; Accepted July 4, 2012)

To verify scientifically whether the non-threshold concept of genotoxic carcinogenicity is valid, we examined the hepatocarcinogenicities at low doses of three genotoxic carcinogens: 2-amino-3, 8 dimethylimidazo[4,5- $f$ qquinoxaline (MelQx), 2-amino-3-methylimidazo[4,5-f]quinoline (IQ) and $\boldsymbol{N}$-nitrosodiethylamine (DEN) using a mediumterm rat hepatocarcinogenicity bioassay. We also examined alterations of molecular markers that cells typically acquire as they move through the initiation and promotion stages of carcinogenesis. We found that low doses of MelQx induced formation of DNA-MelQx adducts, somewhat higher doses caused elevation of oxidative DNA damage, at further higher doses gene mutations occurred; and the very highest dose of MelQx induced formation of glutathione $S$-transferase placental form (GST-P) positive foci in the liver, a well-known preneoplastic lesion marker in rat hepatocarcinogenesis. Similarly, low doses of $I Q$ and DEN had no effect on formation of GST-P positive foci in the rat liver. Furthermore, we demonstrated that concurrent treatment with combinations of sub-carcinogenic doses of MelQx and DEN were not hepatocarcinogenic and the combined effects were neither additive nor synergistic. Moreover, concurrent treatment with low carcinogenic doses of these $\mathbf{2}$ carcinogens did not show additive or synergistic effects, and synergetic effects were observed only in rats co-administered high doses of those 2 carcinogens. These findings demonstrated the existence of no effect levels for these genotoxic hepatocarcinogens, and suggested that there is a threshold, at least a practical threshold, that should be considered when evaluating the risk of exposure to genotoxic carcinogens.

Key words: carcinogenic threshold, genotoxic hepatocarcinogens, no additive or synergistic effects, MelQx, IQ, DEN

\section{Introduction}

It has been generally considered that genotoxic carcinogens have no threshold in exerting carcinogenic potential. The dose response curve generated by nonthreshold approach modeling is the S-shaped and linear low-dose straight line that reaches zero. However, this is a theory and there are limited data available for estimation of cancer risk assessment in humans exposed to genotoxic carcinogens (1). The presence or absence of the carcinogenic threshold will determine the reliability of risk assessment of chemical carcinogens when extrapolated from high dose rodent testing. Therefore, the non-threshold theory for genotoxic carcinogens can be challenged in animal carcinogenic studies. To test this hypothesis, we have examined low dose carcinogenicities of the genotoxic carcinogens in rats over the past 10 years from the viewpoint of cancer risk assessment and management (2). In this symposium, we have presented and discussed the major findings of our low-dose carcinogenicity studies. Most genotoxic carcinogens are metabolized in the target cells to their active form, which is known as an ultimate carcinogen. The ultimate carcinogens bind covalently to DNA, forming adducts, later resulting in occurrence of DNA mutation which is an irreversible change. This sequence of genetic events is thought to occur during the initiation stage in two-stage chemical carcinogenesis model. Of course, DNA repair, cancer-unrelated mutations, apoptosis, etc., influence this carcinogenic process in living organisms. Thereafter, the initiated cells (mutated cells) proliferate to preneoplastic lesions which finally develop into tumors. This development of initiated cells into tumors is known as the promotion stage in two-stage chemical carcinogenesis model. In the present studies, we focused on the above-mentioned carcinogenic events in low-dose genotoxic chemical carcinogenesis to clarify whether a carcinogenic threshold exists or not.

\section{Low-dose Carcinogenicity of MelQx in the Rat Liver}

MeIQx is a heterocyclic amine contained in burned fish and meat. MeIQx at 100-400 ppm in the diet exerts

${ }^{3}$ Correspondence to: Shoji Fukushima, Japan Bioassay Research Center, Japan Industrial Safety \& Health Association, Hadano, Kanagawa 257-0015, Japan. Tel: +81-463-82-3911, Fax: +81-463-82-3860, E-mail: s-fukushima@jisha.or.jp doi: 10.3123 /jemsge. 34.153 
carcinogenicity in the rat liver (3). To examine the carcinogenic potential of MeIQx in the rat liver, 1145 21day-old male F344 rats were given MeIQx in the diet at doses of $0,0.001,0.01,0.1,1,10$, and $100 \mathrm{ppm}$ for $4-32$ weeks (4). The formation of MeIQx-DNA adducts in the liver at week 4 was induced by $0.01-100 \mathrm{ppm}$, this induction was dose-dependent and significant at 100 ppm. Alterations to MeIQx-DNA adduct formation at week 16 were similar to that of week 4 . Interestingly, MeIQx induced 8-hydroxy-2'-deoxyguanosine (8$\mathrm{OHdG}$ ), which is a marker of oxidative damage. 8OHdG levels in hepatic DNA at week 4 were significantly elevated in the groups of MeIQx at doses of 1, 10, and $100 \mathrm{ppm}$, when compared to the control. Similar results were obtained at week 16 of MeIQx administration. Numbers of glutathione $S$-transferase-placental positive foci (GST-P positive foci), which are the preneoplastic lesions in rat hepatocarcinogenesis $(5,6)$, were significantly increased in the $100 \mathrm{ppm}$ group treated with MeIQx for 16 and 32 weeks. Furthermore, MeIQx significantly increased mutation frequency of the lacI gene in the liver of Big Blue rats treated with doses of 10 and $100 \mathrm{ppm}$ for 16 weeks (7). In this experiment, GST-P positive foci were significantly increased at $100 \mathrm{ppm}$ group of MeIQx. To examine initiation activity of MeIQx in the rat liver, male 21-day-old F344 rats were administered MeIQx at doses of 0.001 to $100 \mathrm{ppm}$ for 4 weeks and followed by administration of $500 \mathrm{ppm}$ phenobarbital in the diet. Significant increases of GST$P$ positive foci were detected in the 10 and $100 \mathrm{ppm}$ MeIQx groups, indicating the existence of a no-effect level for MeIQx initiation activity (8). These findings are summarized in Fig. 1.

\section{Low-dose Carcinogenicity of IQ in the Rat Liver}

IQ is also a heterocyclic amine contained in burned fish and meat which has been shown to exert hepatocarcinogenicity in rats (9). To examine its carcinogenic potential in the liver at low dose levels, 1595 21-day-old

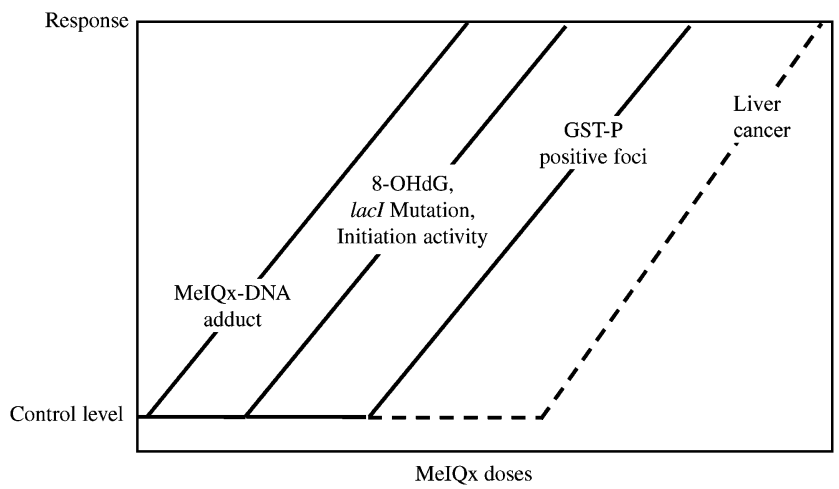

Fig. 1. Risk of liver cancer: Reaction curves for carcinogenesis markers are dependent on the dose of MeIQx.
F344 rats were given IQ in the diet at doses of $0,0.001$, $0.01,0.1,1,10$ and $100 \mathrm{ppm}$ for 16 weeks (10). Numbers of GST-P positive foci were significantly increased at doses of 10 and $100 \mathrm{ppm}$ (Fig. 2). The formation of IQ-DNA adducts at week 4 was induced in dose-dependent manner from $0.01 \mathrm{ppm}$ to $100 \mathrm{ppm}$, although not statistically significantly because of the small number of samples in each group (Fig. 3). p2 $1^{\mathrm{Cip} / \mathrm{WAFI}}$ mRNA expression was significantly increased at $0.01 \mathrm{ppm}$ and above. In contrast, mRNA expression levels of PCNA, APE-1 and GADD45 were significantly elevated only at $10 \mathrm{ppm}$ and/or $100 \mathrm{ppm}$. The above findings are summarized in Fig. 4.

\section{Low-dose Carcinogenicity of DEN in the Rat Liver}

DEN is synthesized in the stomach through the reac-

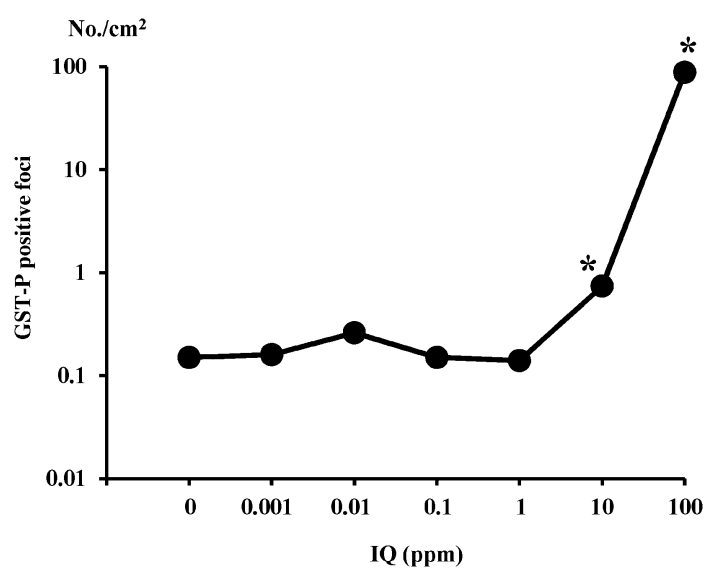

Fig. 2. GST-P positive foci in the livers of F344 rats treated with IQ at various doses for 16 weeks. *Significantly different from 0 ppm group. Values are shown on a logarithmic scale.

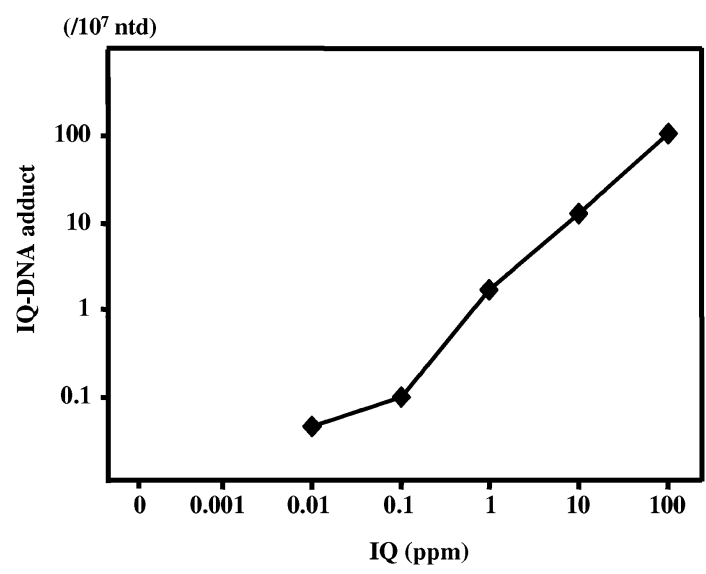

Fig. 3 IQ-DNA adduct formation in the liver of F344 rats treated with IQ at various doses for 4 weeks. IQ-DNA adduct levels at 0 and $0.001 \mathrm{ppm}$ groups were under the detection limit $\left(5 \times 10^{-10} \mathrm{ntd}\right)$. Values are shown on a logarithmic scale. 


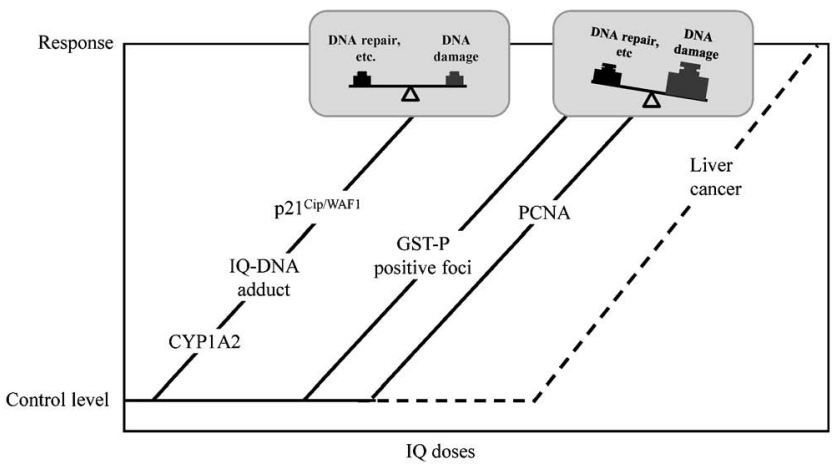

Fig. 4. Risk of liver cancer: Reaction curves for carcinogenesis markers are dependent on the dose of IQ.

tion of secondary amines and nitrites in the diet. DEN is also found as a contaminant in a variety of manufactured food products. Previously, Peto et al. (1) examined the hepatocarcinogenicity of DEN in drinking water at doses of $0.033-16.896 \mathrm{ppm}$ using $2000 \mathrm{Col}-$ worth rats. Their results indicated that DEN had no threshold for carcinogenicity in the rat liver. However, the lowest dose employed was still quite high. Therefore, we re-examined the carcinogenic potential of DEN at low-dose levels for the rat liver (4). A total of 1957, 21-day-old male F344 rats were administered DEN at doses of 0.0001 to $10 \mathrm{ppm}$ in their drinking water for 16 weeks. Numbers of GST-P positive foci in the liver were significantly increased at $0.1 \mathrm{ppm}$ and above. These results indicated that there is a no-effect level for DEN hepatocarcinogenicity in the rat.

\section{Low-dose Carcinogenicity by Concurrent Treatment of MelQx and DEN in the Rat Liver}

Concurrent carcinogenic responses of genotoxic carcinogens were reported to show additive or synergistic effects at high dose levels. However, there are few of carcinogenicity studies of concurrent treatment at low dose levels, and the exposure levels of carcinogens examined are still high compared to the exposure levels in our environment. Therefore, we evaluated the carcinogenicity of concurrent treatment with low-doses of MeIQx and DEN in the rat liver (11).

Experiment 1 was designed to evaluate the hepatocarcinogenicity of concurrent treatment with various doses of MeIQx at the dose of a maximum no-effect level for the DEN observed in our previous study (4). A total of 400, 21-day-old male F344 rats were given MeIQx in their diet at doses of $0,0.01,0.1,1,10$, and $100 \mathrm{ppm}$, and DEN at a dose of $0.01 \mathrm{ppm}$ in the drinking water for 16 weeks, concurrently or alone. As shown in Fig. 5, in the MeIQx alone treatment groups, the number of GST-P positive foci developed in groups administered 0.01 to $10 \mathrm{ppm}$ did not differ from the non-treatment control group, in contrast to the significant increase in

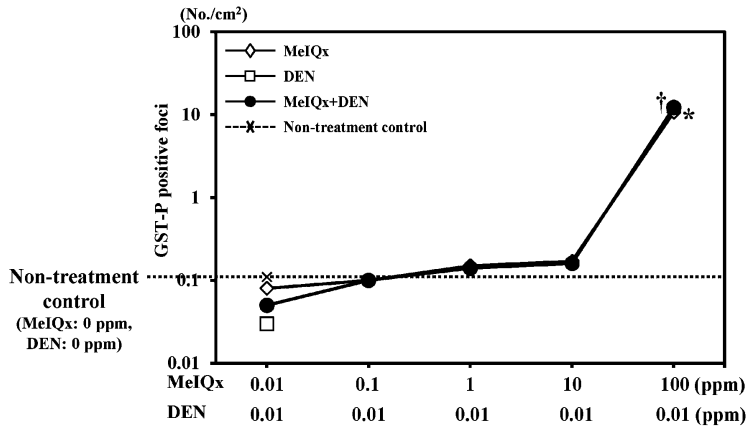

Fig. 5. Effects of concurrent treatment of a sub-carcinogenic dose of DEN $(0.01 \mathrm{ppm})$ on rat hepatocarcinogenesis induced by various doses of MeIQx. *MeIQx alone groups: significantly differed from non-treatment control; ${ }^{\dagger} \mathrm{DEN}+\mathrm{MeIQx}$ groups: significantly differed from non-treatment control. Values are shown on a logarithmic scale.

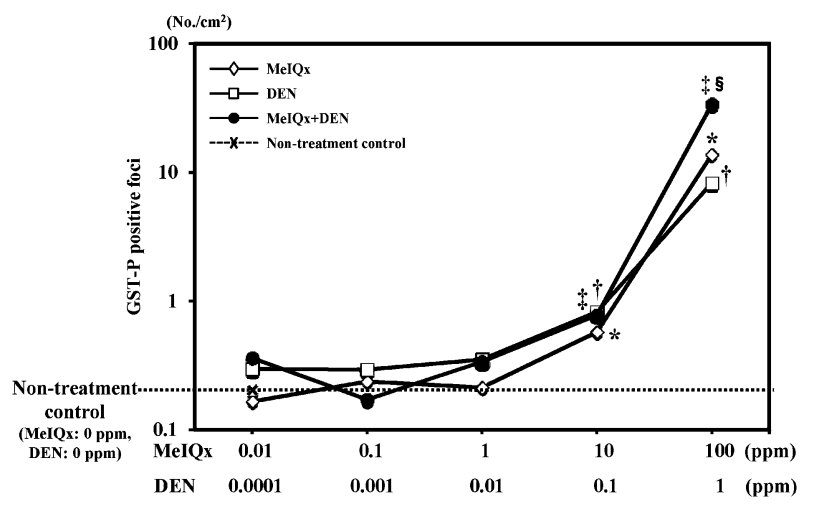

Fig. 6. Effects of concurrent treatment of various doses of MeIQx and DEN. *MeIQx alone groups; significantly differed from nontreatment control; ${ }^{\dagger} \mathrm{DEN}$ alone groups: significantly differed from non-treatment control; ${ }^{\star} \mathrm{DEN}+\mathrm{MeIQx}$ groups: significantly differed from non-treatment control; \$Significantly differed from respective MeIQx and DEN alone group. Values are shown on a logarithmic scale.

the $100 \mathrm{ppm}$ MeIQx group. Concurrent treatment with $0.01 \mathrm{ppm}$ DEN did not promote induction of GST-P positive foci in groups of MeIQx at various doses. Namely, DEN at $0.01 \mathrm{ppm}$ did not exert an additive or synergistic effect on induction of GST-P positive foci.

Experiment 2 was designed to evaluate the development of GST-P positive foci of concomitant treatments with MeIQx and DEN at sub-carcinogenic doses. A total of 390, 21-day-old, male F344 rats were given MeIQx in the diet at doses of $0,0.01,0.1,1,10$, and 100 ppm or DEN at doses of $0.0001,0.001,0.01,0.1$ and 1 ppm concomitantly or alone. The doses of DEN were the same as in our previous DEN-low dose study (4). As shown in Fig. 6, the number of GST-P positive foci in the groups administered MeIQx at doses of $0.01 \mathrm{ppm}$ to $1 \mathrm{ppm}$ and those administered DEN at doses of 0.0001 to $0.01 \mathrm{ppm}$ did not differ from the non-treatment control. Furthermore, the number of GST-P positive foci in 
groups administered combinations of sub-carcinogenic doses of MeIQx and DEN (0.01 ppm MeIQx + 0.0001 ppm DEN, $0.1 \mathrm{ppm}$ MeIQx $+0.001 \mathrm{ppm}$ DEN and 1 ppm MeIQx $+0.01 \mathrm{ppm}$ DEN groups) did not differ from either the respective single treatments or the nontreatment control group. In contrast, in the MeIQx and DEN alone treatment groups, significant increases of GST-P positive foci numbers were observed in groups administered $10 \mathrm{ppm}$ and $100 \mathrm{ppm}$ MeIQx and in groups administered $0.1 \mathrm{ppm}$ and $1 \mathrm{ppm}$ DEN. Moreover, there were no significant alterations in the number of GST-P positive foci between $10 \mathrm{ppm}$ MeIQx $+0.1 \mathrm{ppm}$ DEN group compared to $10 \mathrm{ppm}$ MeIQx alone or $0.1 \mathrm{ppm}$ DEN alone groups, indicating that the hepatocarcinogenicity of these two carcinogens combined at low doses was not enhanced additively or synergistically. In contrast, number of GST-P positive foci in the high dose combination group, $100 \mathrm{ppm}$ MeIQx +1 ppm DEN group, was synergistically increased compared to their respective single treatment groups. These results demonstrated that concurrent treatment with non-carcinogenic doses of DEN and MeIQx did not exert hepatocarcinogenicity in rats and their combined effects were neither additive nor synergistic.

\section{Conclusion}

Our findings indicate that the dose response in these three genotoxic carcinogens are non-linear and suggest that there is a threshold, at least a practical threshold, which should be considered when evaluating the risk of genotoxic carcinogens. High dose-response relationships for low dose genotoxic carcinogens, especially for mixtures of carcinogens, are still controversial within the field of carcinogen risk assessment. Further accumulation of data, especially mechanistic data, should be encouraged to facilitate not only our understanding of carcinogenic effects of genotoxic carcinogens at low doses, but also to establish accurate means of risk assessment.

Acknowledgements: The authors would like to acknowledge the encouragement of Dr. N. Ito (The Late Prof. Emeritus, Nagoya City University Medical School, Nagoya, Japan) and Dr. T. Kitagawa (Director Emeritus, the Cancer Institute of Japanese Foundation for Cancer Research, Tokyo). This research was supported by a grant from the Project of Core Research for Evolutional Science and Technology (CREST).

\section{References}

1 Peto R, Gray R, Brantom P, Grasso P. Effects on 4080 rats of chronic ingestion of $\mathrm{N}$-nitrosodiethylamine or $\mathrm{N}$ nitrosodimethylamine: a detailed dose-response study. Cancer Res. 1991; 51: 6415-51.

2 Fukushima S, Wei M, Kakehashi A, Wanibuchi $H$. Thresholds for genotoxic carcinogens: evidence from mechanism-based carcinogenicity studies. In: $\mathrm{Hsu} \mathrm{CH}$, Stedeford T, editors. Cancer risk assessment. New Jersey: John Wiley \& Sons, Inc.; 2010. p. 207-21.

3 Kato T, Ohgaki H, Hasegawa H, Sato S, Takayama S, Sugimura T. Carcinogenicity in rats of a mutagenic compound, 2-amino-3,8-dimethylimidazo[4,5- $f$ ]quinoxaline. Carcinogenesis. 1988; 9: 71-3.

4 Fukushima S, Wanibuchi H, Morimura K, Wei M, Nakae $\mathrm{D}$, et al. Lack of a dose-response relationship for carcinogenicity in the rat liver with low doses of 2-amino-3,8dimethylimidazo[4,5- $f$ ]quinoxaline or $N$-nitrosodiethylamine. Jpn J Cancer Res. 2002; 93: 1076-82.

5 Ito N, Tsuda H, Tatematsu M, Inoue T, Tagawa $\mathrm{Y}$, et al. Enhancing effect of various hepatocarcinogens on induction of preneoplastic glutathione $S$-transferase placental form positive foci in rats-an approach for a new medium-term bioassay system. Carcinogenesis. 1988; 9: 387-94.

6 Tsuda H, Fukushima S, Wanibuchi H, Morimura K, Nakae D, et al. Value of GST-P positive preneoplastic hepatic foci in dose-response studies of hepatocarcinogenesis: evidence for practical thresholds with both genotoxic and nongenotoxic carcinogens. A review of recent work. Toxicol Pathol. 2003; 31: 80-6.

7 Hoshi M, Morimura K, Wanibuchi H, Wei M, Okochi E, et al. No-observed effect levels for carcinogenicity and for in vivo mutagenicity of a genotoxic carcinogen. Toxicol Sci. 2004; 81: 273-9.

8 Fukushima S, Wanibuchi H, Morimura K, Wei M, Nakae $\mathrm{D}$, et al. Lack of initiation activity in rat liver of low doses of 2-amino-3,8-dimethylimidazo[4,5- $f$ ]quinoxaline. Cancer Lett. 2003; 191: 35-40.

9 Ohgaki H, Kusama K, Matsukura N, Morino K, Hasegawa $\mathrm{H}$, et al. Carcinogenicity in mice of a mutagenic compound, 2-amino-3-methylimidazo[4,5- $f$ ]quinoline, from broiled sardine, cooked beef and beef extract. Carcinogenesis. 1984; 5: 921-4.

10 Wei M, Wanibuchi H, Nakae D, Tsuda H, Takahashi S, et al. Low-dose carcinogenicity of 2-amino-3-methylimidazo[4,5- $f$ ]quinoline in rats: Evidence for the existence of no-effect levels and a mechanism involving p21(Cip/WAF1). Cancer Sci. 2011; 102: 88-94.

11 Wei M, Kakehashi A, Yamano S, Tamano S, Shirai T, et al. Lack of hepatocarcinogenicity of combinations of low doses of 2-amino-3,8-dimethylimidazo[4,5- $f$ ]quinoxaline and diethylnitrosamine in rats: indication for the existence of a threshold for genotoxic carcinogens. J Toxicol Pathol. 2012; 25: 209-14. 